\title{
A Influência do Tamanho da Empresa na Informação Contábil: Evidências em Empresas Large Caps e Small Caps Listadas na BM\&FBovespa
}

\begin{abstract}
Resumo
O presente trabalho investigou a relação de aspectos da informação contábil com o nível de capitalização das empresas listadas na Bolsa de Valores de São Paulo, classificadas em Large Caps ou Small Caps, empresas de maior e menor capitalização, respectivamente, no período de 2010 a 2012. Foram abordadas três métricas da informação contábil: informatividade, conservadorismo e relevância, por meio da aplicação dos modelos da informatividade dos lucros de Easton e Harris (1991), o modelo de conservadorismo condicional de Basu (1997) e o modelo de value relevance, baseado em Ohlson (1995). Os resultados apontaram que embora as Large Caps apresentem maior grau de conservadorismo, seus números contábeis mostraram-se menos informativos e mais relevantes em comparação às Small Caps. Devido à maior produção de informação privada (predisclosure) em torno das empresas de maior porte, o mercado tenderia a responder com menos força ou surpresa à publicação das informações contábeis dessas empresas, ao passo que a própria escassez de informação antecipada, tornaria o efeito da divulgação desses números mais preponderante para as empresas de menor porte (Small Caps).
\end{abstract}

Palavras chave: Níveis de Capitalização; Porte das Empresas; Aspectos da Informação Contábil.

\author{
Karen Yukari Yokoyama \\ Mestra em Ciências Contábeis pela \\ Universidade Federal do Espírito Santo - \\ UFES. Contato: Av. Fernando Ferrari, 514 - \\ CCJE, ED VI, SL 618 - Campus Universitário. \\ Vitória-ES. CEP: 29.075-910. \\ E-mail: karen.yukari@gmail.com
}

Vitor Gomes Baioco

Mestre em Ciências Contábeis pela Universidade Federal do Espírito Santo UFES. Contato: Av. Fernando Ferrari, 514 CCJE, ED VI, SL 618 - Campus Universitário. Vitória- ES. CEP: 29.075-910.

E-mail: vitorbaioco@gmail.com

\section{William Brasil Rodrigues Sobrinho}

Mestre em Ciências Contábeis pela Universidade Federal do Espírito Santo UFES e Professor do Instituto Federal de Educação, Ciência e Tecnologia do Tocantins (IFTO). Contato: Av. Joaquim Teotônio Segurado, Qd 202 Sul, ACSU-SE 20, Cj 01 Lote 08 - Sul Palmas- TO. CEP: 77.020-450. E-mail: william@ifto.edu.br

\section{Alfredo Sarlo Neto}

Doutor em Controladoria e Contabilidade pela Universidade de São Paulo (FEA/ USP) e Professor Adjunto da Universidade Federal do Espírito Santo (UFES). Contato: Av. Fernando Ferrari, 514 - CCJE, ED VI, SL 618 - Campus Universitário. Vitória- ES. CEP: 29.075-910.

E-mail: sarloneto@ccje.ufes.br 


\section{Introdução}

O estudo sobre a importância das informações contábeis, especialmente em mercados emergentes, está em consonância com pesquisas internacionais e nacionais contemporâneas (Almeida, 2010; Fan-fah, Mohd, \& Nasir, 2008; Lima, 2011; Lopes, 2002) que examinam a importância da qualidade da informação contábil para os usuários externos e suas determinantes, à medida que se desenvolve o mercado de capitais nesses países.

Estudos acadêmicos buscaram evidências do impacto de características específicas das empresas em diversos aspectos da informação contábil, entre as quais o porte da empresa, tal como em Collins, Kothari e Rayburn (1987); Fan-fah et al. (2008); Papadatos e Bellas (2011) e Kouser, Awan, Gul-e-Rana e Shahzad (2011).

Collins et al. (1987) constataram que trabalhos teóricos e empíricos sugerem uma correlação positiva entre o valor de capitalização de uma empresa e o montante de informação disseminada no mercado.

Consistente com essas investigações e adotando como métrica à classificação por porte de capitalização usual em mercado de capitais (Large Caps e Small Caps), tece-se, então, o seguinte problema de pesquisa: Como o porte da empresa, medido pelo nível de capitalização, influencia as informações contábeis divulgadas pelas empresas negociadas na BM\&FBovespa?

Para este estudo, foram utilizadas, a partir da aplicação de modelos consagrados, as seguintes análises: informatividade dos lucros, conservadorismo condicional e value relevance, pelo fato de demonstrarem atributos como relevância e tempestividade das informações divulgadas no mercado de capitais. Assim, este trabalho tem como objetivo analisar as diferentes propriedades das informações contábeis, no período de 2010 a 2012, divulgadas sob o contexto do nível de capitalização das empresas brasileiras.

O modelo de informatividade, baseado em Easton e Harris (1991), expressa a relação entre retorno das ações e lucro contábil - quanto maior for essa relação, maior será a informatividade do lucro (Sarlo Neto, 2009). Apoiado em Ohlson (1995), o modelo do value relevance, analisa a relevância das demonstrações contábeis pela força de associação entre os números contábeis: patrimônio líquido e lucro anormal sobre o preço da ação. Assim, quanto mais forte o poder preditivo dessas variáveis, maior será a relevância da informação contábil. O modelo de conservadorismo foi estruturado a partir do trabalho de Basu (1997), o qual se apoia na tese de que "o lucro reflete as más notícias mais rapidamente do que as boas", de modo que a relação entre o lucro e o retorno das ações é mais forte quando estes são negativos.

O artigo está dividido em duas partes. Primeiramente, serão apresentados os principais fundamentos teóricos que embasaram o presente estudo, investigando-se, na literatura contábil e financeira, considerações acerca da associação entre o porte das empresas e a capacidade informacional dos números contábeis. Na segunda parte, desenvolve-se o estudo empírico, a partir de empresas listadas na Bolsa de Valores de São Paulo (BM\&FBovespa), classificadas segundo o índice que leva em consideração o valor de capitalização. Será abordado nesse tópico o desenvolvimento das hipóteses de sua pesquisa, bem como apresentada breve conceituação teórica de cada modelo empregado, seguida de explanação detalhada da metodologia de coleta e tratamento de dados. Discorre-se, ao final, sobre os principais resultados encontrados por meio das regressões multivariadas e, consequentes, conclusões.

Embora sejam encontrados na literatura internacional estudos que buscaram investigar a relação do tamanho das empresas a aspectos da informação contábil, a abordagem pelo porte de capitalização das empresas em bolsa verificou-se pouco explorada, havendo, portanto, importante espaço para contribuição científica, especialmente no Brasil, onde a produção relativa a esse tema específico é escassa. O efeito tamanho, presente na literatura, estuda o impacto do tamanho da empresa sobre a informação contábil, com base em uma métrica contábil, sendo usualmente utilizado o ativo ou a receita. Porém, de forma alternativa, este trabalho adota, como métrica, a capitalização das empresas, que diferentemente das métricas contábeis, possui a capacidade de refletir as expectativas do mercado em relação ao seu valor de mercado. 


\section{Referencial Teórico}

\subsection{A Influência do tamanho da empresa na informação contábil}

O efeito do tamanho da firma sobre valor de mercado das empresas é tema bastante estudado na literatura internacional, não havendo consenso definitivo quanto a essa relação (Banz, 1981; Dijk, 2011). Uma corrente de pesquisas interpreta o tamanho da empresa como uma proxy para a quantidade de informações disponíveis sobre ela, as quais podem interferir na relevância das informações contábeis. A seguir, são descritos os resultados encontrados por esses autores.

Atiase (1985) sugere que o retorno do preço das ações é inversamente proporcional ao tamanho da empresa, usando como proxy o valor de mercado das ações ordinárias. A hipótese proposta seria que a produção de informações privadas é uma função crescente do tamanho da empresa. Grandes empresas oferecem uma maior demanda de informações, pelo fato de atrair maior interesse de investidores, analistas e imprensa. Dessa forma, a quantidade de informações contidas nos anúncios dos lucros contábeis é maior em empresas com menor predisclosure de informações específicas, e que a resposta nos preços seria menor em empresas consideradas visadas pelo mercado. Diferente da abordagem de tamanho da empresa, mas com entendimento similar, Grant (1980) compara empresas com maior e menor predisclosure de informações específicas e chega a conclusões semelhantes quando do anúncio dos lucros contábeis.

Freeman (1987), em consonância com Atiase (1985), verificou, a partir de estudos empíricos, que os preços das ações em empresas grandes (de maior capitalização) tendem a antecipar mais rapidamente os lucros contábeis do que as de menor porte. Segundo o pesquisador, empresas grandes possuem maior demanda de informação por parte de investidores e analistas, que estariam dispostos a empregar recursos para gerar informações não contábeis que apoiem os dados contábeis e financeiros disponíveis. Além disso, empresas maiores costumam ser foco de atenção da mídia especializada e de exigências de divulgação por órgãos reguladores, ampliando as informações existentes para previsão mais acurada dos lucros futuros. Segundo o autor, espera-se que enquanto os custos marginais de informação foram inferiores ao lucro com a transação apoiada nessas informações, haverá incentivo para produção de informação. Freeman (1987) examinou também a magnitude dessas relações, comprovando, empiricamente, a hipótese de que como se espera que as informações não contábeis estejam concentradas em empresas maiores, o valor de mercado de empresas menores esteja mais provavelmente baseado nas próprias informações contábeis (série histórica do lucro não ajustado). Haveria, portanto, uma relação inversa entre o tamanho da firma e a magnitude dos retornos anormais, relativos às boas e más notícias associadas ao lucro contábil (Freeman, 1987).

Collins et al. (1987) investigaram o conteúdo informacional do preço da ação para diferentes tamanhos de empresas (valor de capitalização), confirmando, por meio de testes empíricos, a hipótese teórica de que empresas maiores possuem maior quantidade de informação disponível e provável maior quantidade de profissionais analisando as informações existentes, de modo que, ceteris paribus, maior seria a informatividade contida nos preços das ações.

Dijk (2011) revisou a literatura científica quanto ao efeito do tamanho da empresa sobre o retorno da ação, concluindo que há resultados contraditórios sobre a existência desses efeitos, de modo que a produção de estudos empíricos sobre o tema é ainda relevante para a robustez dos resultados encontrados. Citou, por exemplo, resultados como o de Banz (1981) e Chan, Hamao e Lakonishok (1991).

Banz (1981) examinou o efeito do tamanho nos retornos, usando como proxy do porte o valor de mercado das empresas. O autor investigou a hipótese de que os retornos são maiores em empresas de menor porte, uma vez que os investidores evitam manter por muito tempo ações dessas empresas devido à escassez de informação. Sendo o efeito do tamanho da empresa, não linear e mais acentuada em empresas de menor porte, enquanto não foi encontrada diferença significativa entre empresas de médio e grande porte.

Chan et al. (1991) estudaram o tamanho da empresa como uma das variáveis fundamentais no retorno das ações em empresas da bolsa de valores de Tóquio. Na análise realizada, verificaram que a variável era signi- 
ficativa e o efeito mais pronunciado em empresas de menor porte. Observaram, ainda, que a significância dessa variável é bastante sensível ao modelo de análise especificado, podendo ser não significativa em alguns modelos.

Outra corrente de pesquisa muito forte prevê que grandes empresas usaram de técnicas para gerenciar resultados com maior frequência do que pequenas empresas, na maior parte das vezes, visando redução dos lucros presentes. Isso ocorre pelo fato de o tamanho ser um estimador da atenção política que a empresa pode receber. Se os administradores perceberem que a empresa está sob forte observação de natureza política, o que pode acarretar custos elevados, eles podem optar por procedimentos contábeis para postergar os lucros presentes. Essa atitude parte do pressuposto de que lucros elevados atraem atenção de órgãos reguladores, imprensa, ambientalistas e outros (Iudícibus \& Lopes, 2008).

Os resultados da pesquisa de Jones (1991) comprovam a hipótese de que empresas grandes, consequentemente mais visíveis politicamente, adotam, em sua maioria, procedimentos contábeis que visam à redução dos lucros presentes. Estudos similares, como de Wong (1988) e Sutton (1988), sustentam a hipótese que relaciona o grau de visibilidade com a qualidade dos lucros.

Watts e Zimmerman (1979) afirmam que o conteúdo das demonstrações contábeis no processo regulatório influencia as comissões de governo, assim como ações legislativas, fornecendo incentivos para discricionariedade por parte dos administradores nos procedimentos contábeis, que visam à diminuição dos custos políticos ou aumento de benefícios advindos das decisões regulatórias.

\subsection{Firmas Large Caps e Small Caps}

A principal diferença entre empresas consideradas Small Caps e Large Caps diz respeito ao nível de capitalização. Empresas que possuem maior capitalização são denominadas Large Caps, enquanto as empresas com capitalização menor são classificadas de Small Caps. Em outras palavras, empresas de grande porte, com alto volume de negociações diárias de seus papéis (alta liquidez) são consideradas Large Caps, enquanto empresas com baixa procura de seus ativos, e geralmente com baixa liquidez no mercado de capitais, são consideradas Small Caps. No Brasil, a BM\&FBovespa possui dois índices para indicar esse comportamento: o Mid-Large Cap (MLCX) e o Small Cap (SMLL).

No contexto do mercado de ações Europeu, Glaser e Schaarschmidt (2012) afirmam que as ações com baixa capitalização no mercado, consideradas Small Caps, passaram a receber interesse dos investidores. Logo, estes procuram ativos com fraca correlação ao diversificar suas carteiras. Os autores ainda comentam que ações consideradas Small Caps podem ser consideradas como uma classe de ativos autônoma, pois Eun, Huang e Lai (2008) ao sugerirem que o mecanismo de retorno das Large Caps e Small Caps são diferentes, argumentam que o retorno daquelas é impulsionado por fatores globais comuns, enquanto o das Small Caps é impulsionado por fatores e características idiossincráticas locais.

Eun et al. (2008) também apontam a influência dos investidores, especialmente os investidores institucionais, que acompanham índices de mercado e contribuem para a tendência de capitalização das ações consideradas Large Caps.

\subsection{Métricas Contábeis}

Os estudos elaborados no mercado brasileiro sobre a importância das informações contábeis e sobre a qualidade das informações contábeis foram desenvolvidos sobre métricas consagradas pela literatura internacional, tais com Value Relevance (Relevância), Timeliness (Tempestividade), Informativeness (Informatividade) e Conservadorismo. Entre muitos trabalhos desenvolvidos a partir de alguma dessas métricas, podemos citar: Costa, Lopes e Costa (2006), Sarlo Neto, Rodrigues e Almeida (2010); Almeida, Sarlo Neto, Bastianello e Moneque (2012); Hungarato e Lopes (2008); Macedo, Machado, Murcia e Machado (2011) e Brugni, Neto, Bastianello e Paris (2012) 
Recentemente, Dechow, Ge e Schrand (2010) elaboraram um extenso estudo sobre as diversas proxies utilizadas na literatura internacional para mensurar a qualidade da informação contábil. As proxies levantadas neste estudo foram classificadas em 3 (três) categorias: (i) Propriedades do Lucro (properties of earnings); (ii) Resposta dos Investidores ao Lucro (investors responsiveness to earnings); e (iii) Indicadores Externos de Divulgação Inadequada (external indicators of misstatements).

Considerando o universo de métricas apresentadas por Dechow et al. (2010), este trabalho adota um número de métricas mais restrito, utilizadas em um grande número de trabalhos presentes na literatura brasileira. Dentro da preposta de Dechow et al. (2010), as métricas Value Relevance e Conservadorismo seriam classificadas na categoria Propriedades do Lucro, e a Informatividade, na categoria Resposta dos Investidores do Lucro.

\subsubsection{Informatividade dos lucros}

A importância da informação contábil vem sendo estudada por meio de análises de variáveis contábeis utilizadas para a apresentação aos seus diversos usuários. Entre as variáveis: "patrimônio líquido" e "resultado" (lucro ou prejuízo), foram encontradas evidências de que possuem capacidade informacional (Lopes \& Martins, 2005).

Seguindo esse pensamento, o lucro contábil, devido ao seu poder na mensuração de desempenho, recebe considerável atenção por parte dos usuários da informação contábil tornando-se útil para os investidores no momento em que estes utilizam o lucro como informação para ajustar as suas expectativas. Contendo novas informações, o lucro pode provocar ajustes nas expectativas dos investidores e, consequentemente, nos preços das ações (Sarlo Neto, 2009).

Partindo do pressuposto da relação entre a informação contábil e o preço das ações, a informatividade dos lucros pode ser representada pela associação entre o retorno das ações e o lucro contábil.

A fundamentação teórica que busca explicar a importância das informações contábeis (lucro e patrimônio) com o retorno das ações surgiu na década de 60 com os pioneiros Ball e Brown (1968) e Beaver (1968), que verificaram a reação do mercado quanto à divulgação de informações contábeis que continham novas informações ainda não conhecidas pelo mercado, e que podiam alterar a expectativa dos investidores. Esses estudos impulsionaram novas pesquisas e desenvolvimento de modelos sobre o impacto do lucro contábil nos preços das ações, como Easton e Harris (1991) e Francis e Schipper (1999).

Alguns trabalhos desenvolvidos na última década procuraram verificar a influência de diversos aspectos sobre a informatividade dos lucros. Estudos ambientados no mercado americano, como o de Francis, Schipper e Vincent (2005) pesquisaram a informatividade dos lucros contábeis e os dividendos, com a presença de divergências entre os direitos de voto e de fluxo de caixa, e a influência da participação de famílias sobre a informatividade dos lucros contábeis, como os de Wang (2006). No Brasil, Sarlo Neto et al. (2010) investigaram a influência da estrutura de propriedade sobre a informatividade dos lucros divulgados, e Brugni et al. (2012) analisaram o impacto dos dividendos sobre a informatividade dos lucros.

\subsubsection{Relevância da informação contábil (Value Relevance)}

A literatura contábil identifica na relevância uma das características ou propriedades qualitativas da informação contábil (Almeida, 2010), sendo diversas as definições disponíveis (Barth, Beaver, \& Landsman, 2001; Lima, 2011).

O conceito de value relevance adotado nesta pesquisa consiste na tese da capacidade dos números contábeis de resumir ou captar informações subjacentes aos preços das ações. No mesmo sentido, segundo Barth et al. (2001), uma informação contábil será considerada relevante se possui uma associação com o valor de mercado da empresa ou das ações. 
Segundo Liu e Liu (2007), na literatura de value relevance, distinguem-se, principalmente, dois tipos de modelos de avaliação: o modelo do retorno anual, baseado nos estudos de Easton e Harris (1991), o qual relaciona o retorno da ação ao lucro contábil; e o modelo price model, aperfeiçoado a partir do modelo de Ohlson (1995). Segundo Kothari e Zimmerman (1995), estudos empíricos apontaram menor tendenciosidade dos coeficientes relacionados ao lucro no price model em relação ao modelo dos retornos anuais.

O modelo de Ohlson (1995) indica a relação entre o valor de mercado, os lucros anormais futuros e o patrimônio líquido, portanto, agregando informações correntes e futuras (Santos, Lopes \& Silva, 2010).

Considerando a sua aplicação, o modelo Value Relevance, elaborado a partir de Ohlson (1995), possui uma diferença sobre o modelo de informatividade. Enquanto na informatividade o modelo procura associar o retorno (variação dos preços) com a variação do lucro, o modelo de Value Relevance pretende associar o nível de preço com o nível de valores das métricas contábeis, usualmente, Patrimônio Líquido e Lucro Contábil.

O uso de modelos desenvolvidos e aperfeiçoados a partir de Ohlson (1995), nas pesquisas empíricas contábeis, com a finalidade de avaliar o impacto de determinadas características ou condições na qualidade da informação contábil, é citado com frequência tanto na literatura internacional (Holthausen \& Watts, 2001) quanto na literatura nacional (Hungarato \& Lopes, 2008; Macedo et al., 2011), mostrando-se adequado para os objetivos desta pesquisa.

\subsubsection{Conservadorismo contábil}

Conservadorismo, conforme Basu (1997), decorre da tendência de os contadores requererem um maior grau de verificação para reconhecer, nas demonstrações financeiras, as boas notícias do que as más notícias. Dessa forma, o lucro contábil reflete as más notícias mais rapidamente do que as boas notícias. Embora não signifique dizer que todos os fluxos de caixa oriundos de receita devam ser recebidos antes de os lucros serem reconhecidos, há apenas a necessidade de que estes fluxos de caixa sejam verificáveis (Watts, 2003).

Assim, o conservadorismo contábil impacta no reconhecimento assimétrico dos accruals. Logo, as perdas (más notícias) tendem a ser totalmente reconhecidas, ao passo que o mesmo não ocorre com o ganho (boas notícias) (Paulo, Antunes, \& Formigoni, 2008).

Para Watts (2003), o conservadorismo contábil também pode ser visto como uma ferramenta para enfrentar o risco moral, pois pode conter o comportamento oportunista da administração em reportar os números contábeis, bem como reduzir os custos políticos impostos pelos reguladores e standard-setters e ainda os custos de litígios (Watts, 2003). De um modo geral, o conservadorismo busca reduzir a assimetria e proteger os acionistas da expropriação de recursos ou pagamentos em excesso de remunerações dos executivos atreladas ao resultado contábil (Almeida, 2010).

Costa et al. (2006) pesquisaram o conservadorismo contábil em cinco países da América do Sul (Argentina, Brasil, Colômbia, Peru e Venezuela) e constataram a existência de conservadorismo no lucro contábil, decorrente do reconhecimento assimétrico entre as más e boas notícias nos resultados contábeis.

Ao investigarem se as características da estrutura de propriedade das empresas brasileiras, concentração de votos e acordo de acionistas estão associados ao conservadorismo condicional, Sarlo Neto et al. (2010) discorrem que a concentração de votos contribui para diminuir o grau de conservadorismo, enquanto o acordo de acionistas contribui para aumentar. Ao estudar o efeito da regulação no conservadorismo contábil, Costa et al. (2006) rejeitaram a hipótese de as empresas pertencentes a setores regulados serem mais conservadoras.

Por fim, Almeida et al. (2012), ao analisarem a suavização de resultado sob a ótica do conservadorismo condicional, obtiveram as evidências indicativas de que as firmas classificadas como não suavizadoras de resultados são as que possuem maior grau de conservadorismo condicional. 


\section{Metodologia}

\subsection{Modelos e resultados esperados}

Considerando o problema de pesquisa, serão adotados modelos como métricas, para ponderarem aspectos importantes da informação contábil, que consistem na modificação de outros três modelos: conservadorismo, informatividade dos lucros e value relevance. Adicionalmente, foram incluídas ao modelo variáveis de controle: endividamento (END) e market-to-book (MB), com a intenção de isolar seus efeitos sobre a relação das variáveis dependentes e independentes do modelo.

Os modelos foram estimados pelo método dos mínimos quadrados (MQO) e, para mitigar o problema da heterocedasticidade nas regressões, os erros padrões foram ajustados pelo método de White. Não foram detectados problemas relacionados a multicolinearidade.

Para cada métrica foi estimado um modelo principal, com a interação de uma dummy e, em segui$\mathrm{da}$, foram estimadas regressões com os dados em separado. Assim, nos modelos 1.2, 2.2 e 3.2, foram utilizados somente os dados referentes às empresas classificadas como Large Caps, enquanto, para os modelos 1.3, 2.3 e 3.3, foram utilizados somente os dados referentes às empresas classificadas como Small Caps.

\subsubsection{Modelo 1: Conservadorismo contábil}

Conforme Almeida et al. (2012), o modelo parte da premissa de que, no momento do reconhecimento de uma futura perda econômica contida no lucro de uma determinada entidade, o mercado reconhece essa perda oportunamente no retorno das ações. O modelo de Basu (1997) possui a seguinte expressão:

$$
L L A_{i, t}=\beta_{0}+\beta_{1} D_{i, t}+\beta_{2} R E_{i, t}+\beta_{3} D_{i, t} \times R E_{i, t}+\varepsilon_{i, t}
$$

Em que: $L L A_{i, j}=$ lucro líquido do período t, ajustado pelo valor de mercado em t-1. O valor considerado como valor de mercado possui como data-base 31 de março; $D_{i, t}=$ Variável dummy, que será 1 se o retorno econômico for negativo e zero nos demais casos; $R E_{i, t}=$ representa a variação do preço das ações dos doze meses anteriores à data de divulgação do balanço, ajustado pelo pagamento de dividendos - para todas as observações, considerou-se 31 de março como a data-base de publicação das informações contábeis; $\varepsilon_{i, t}$ é o termo de erro; $\beta_{2}$ reflete a oportunidade do lucro contábil, ou seja, o reconhecimento do retorno econômico pelo lucro contábil; e $\beta_{1}$ e $\beta_{3}$ refletem o reconhecimento assimétrico do retorno econômico às boas e más notícias, pelo lucro contábil.

A variável dummy capta a sensibilidade do lucro contábil com relação aos resultados negativos. Os coeficientes de regressão $\beta_{1}$ e $\beta_{3}$, refletem o conservadorismo, enquanto $\beta_{2}$ reflete o reconhecimento do retorno econômico, seja pelo lucro ou prejuízo.

Modelo 1.1: Busca analisar a influência das firmas consideradas Large Caps e Small Caps no conservadorismo contábil das empresas listadas na BM\&FBovespa. A principal modificação é a inclusão da variável dummy Large Caps (LC).

$$
\begin{aligned}
L L A_{i, t}=\beta_{0}+\beta_{1} D_{i, t}+ & \beta_{2} R E_{i, t}+\beta_{3} D_{i, t} \times R E_{i, t}+\beta_{4} L C+\beta_{5} D_{i, t} \times L C+\beta_{\sigma} R E_{i, t} \times L C \\
& +\beta_{7} D_{i, t} \times R E_{i, t} \times L C+\beta_{8} E N D+\varepsilon_{i, t}
\end{aligned}
$$

Em que: $L L A_{i, t}, D_{i, t}, R E_{i, \mathrm{t}}$ correspondem à mesma definição da equação (1); $L C=$ variável dummy assumirá 1 para empresas Large Caps e 0 para as Small Caps; END = Endividamento e $\varepsilon_{i, t}$ é o termo de erro.

Modelos 1.2 e 1.3: Buscam analisar o conservadorismo contábil, separadamente, nas empresas Large Caps e Small Caps, respectivamente, listadas na BM\&FBovespa. 


\subsubsection{Modelo 2: Informatividade dos lucros}

O segundo modelo consiste em uma abordagem que considera a informatividade dos lucros divulgados pela contabilidade como um aspecto qualitativo, em que se busca medir a reação do mercado frente à divulgação dos lucros. Essa abordagem foi utilizada por diversos autores, tal como Easton e Harris (1991), Sarlo Neto (2009) e Wang (2006). A modificação do modelo partiu do pressuposto de que a mensuração da informatividade pode ser condicionada ao porte das empresas, classificadas em Large Caps e Small Caps. O modelo original possui a seguinte expressão:

$$
R A_{i, t}=\beta_{0}+\beta_{1} L L A_{i, t}+\varepsilon_{i, t}
$$

Em que: $R A_{i, t}=$ retorno anormal da ação da empresa i no período t, $\left(R A_{i, t}=R_{i, t}-R M_{t}\right)$ em que $R_{i, t}$ é o retorno da ação da empresa i no período t, e $R M_{t}$ é o retorno do mercado para o período t. Como medida para o retorno do mercado, foi utilizada a variação do índice Mid-Large Cap (MLCX), quando a firma for considerada Large Cap e o índice Small Cap (SMLL), caso a empresa seja considerada uma Small Cap. $L L A_{i, j}=$ lucro líquido do período $t$, ajustado pelo valor de mercado em $\mathrm{t}-1$. O valor considerado como valor de mercado possui como data-base 31 de março; $\varepsilon_{i, t}$ é o termo de erro; $\beta_{1}$ reflete a reação do mercado, frente à divulgação dos lucros.

Modelo 2.1: Busca analisar a influência das firmas consideradas Large Caps e Small Caps na informatividade dos lucros divulgados das empresas listadas na BM\&FBovespa. A principal modificação é a inclusão da variável dummy Large Caps (LC).

$$
R A_{i, t}=\beta_{0}+\beta_{1} L L A_{i, t}+\beta_{2} L C+\beta_{3} L L A_{i, t} \times L C+\beta_{4} L L A \times E N D+\beta_{5} L L A \times M B+\varepsilon_{i, t}
$$

Em que: $R A_{i, t}$ e $L L A_{i, t}$ correspondem à mesma definição da equação (2); $L C=$ Variável dummy assumirá 1 para empresas Large Caps e 0 para Small Caps; Endividamento (END) = valor da relação existente entre o capital de terceiros e o total do ativo no momento $t$, encontrados no balanço patrimonial; e market-to-book $(\mathrm{MB})$ = relação entre o valor de mercado e o valor registrado no patrimônio líquido, sendo 31 de março o mês de referência; $\varepsilon_{i, t}$ é o termo de erro.

Modelos 2.2 e 2.3: Buscam analisar a informatividade dos lucros, separadamente, nas empresas Large Caps e Small Caps, respectivamente, listadas na BM\&FBovespa.

\subsubsection{Modelo 3: Value Relevance}

O terceiro modelo busca mensurar a capacidade preditiva da contabilidade em fornecer uma informação nova, até então não inserida no preço das ações e que seja capaz de alterar a expectativa dos investidores sobre o desempenho futuro da firma. Alterações no preço das ações indicam, assim, maior value relevance da informação contábil (Lopes \& Martins, 2005). O modelo utilizado consiste na alteração do modelo proposto por Ohlson (1995) e busca analisar o impacto informacional do Patrimônio Líquido e do Lucro sobre o preço das ações após a divulgação das demonstrações contábeis, condicionado ao porte da empresa. O modelo inicial possui a seguinte expressão:

$$
P_{i, t}=\beta_{0}+\beta_{1} L P A_{i, t}+\beta_{2} P L A_{i, t}+\varepsilon_{i, t}
$$

Em que: $P_{i, t}=$ preço da ação, ajustado pelos dividendos das ações da firma i, 3 meses após o final do período t $L P A_{i, t}=$ lucro por ação da firma i no período t; $P L A_{i, t}=$ patrimônio líquido por ação da firma i no período t; $\varepsilon_{i, t}$ é o termo de erro; $\beta_{1} e \beta_{2}$ refletem a relevância do lucro e do PL, respectivamente, para os investidores.

Nesse tipo de estudo, verificam-se os coeficientes de regressão das variáveis, de modo que o número contábil é considerado value relevant se seu coeficiente for estatisticamente diferente de zero. 
Modelo 3.1: Busca analisar a influência das firmas consideradas Large Caps e Small Caps na relevância da informação contábil das empresas listadas na BM\&FBovespa. A principal modificação é a inclusão da variável Large Caps (LC).

$$
P_{i, t}=\beta_{0}+\beta_{1} P L A+\beta_{2} L P A_{i, t}+\beta_{3} L C+\beta_{4} P L A_{i, t} \times L C+\beta_{5} L P A_{i, t} \times L C+\beta_{\sigma} M B+\varepsilon_{i, t}
$$

Em que: $P_{i, t} L P A_{i, t} e P L A_{i, t}$ correspondem à mesma definição da equação (3); $L C=$ variável dummy, assumirá 1 para empresas Large Caps e 0 para Small Caps; e market-to-book $(\mathrm{MB})$ = relação entre o valor de mercado e o valor registrado no patrimônio líquido, sendo 31 de março o mês de referência; $\varepsilon_{i, t}$ é o termo de erro.

Modelos 3.2 e 3.3: Buscam analisar a relevância da informação contábil, separadamente, nas empresas Large Caps e Small Caps, respectivamente, listadas na BM\&FBovespa.

\subsection{Hipóteses e resultados esperados}

Assim, considerando as diferentes propriedades da informação contábil, já analisadas no Referencial Teórico, apoiado nas constatações de Jones (1991), quanto à redução dos lucros por grandes empresas, e consequentemente, conservadorismo mais expressivo e de Atiase (1985); Banz (1981) e Freeman (1987), quanto à relação inversa da informatividade e relevância das informações contábeis e o porte das empresas, definido, de acordo com Glaser e Schaarschmidt (2012) em Large Caps (maior capitalização) e Small Caps (menor capitalização), desenvolveram-se as seguintes hipóteses de pesquisa:

$\mathbf{H}_{1}$ : Empresas classificadas como Large Caps possuem maior nível de conservadorismo do que Small Caps.

$\mathbf{H}_{2}$ : Empresas classificadas como Large Caps apresentam menor informatividade nos lucros divulgados do que Small Caps.

$\mathbf{H}_{3}$ : Empresas classificadas como Large Caps possuem menor value relevance do que Small Caps.

Pelo arcabouço teórico e em acordo com as hipóteses de pesquisa desenvolvidas, espera-se que as interações das variáveis de interesse dos modelos de informatividade e value relevance com as variáveis Large Caps (LC) apresentem valores negativos e significativos; já, para o modelo de conservadorismo, valores positivos e significativos. Nos modelos para grupos separados, esperam-se resultados similares ao modelo anterior para as variáveis de interesse em cada grupo, Large Caps e Small Caps, indicando a influência do porte da firma no conservadorismo, na informatividade dos lucros e no value relevance.

Assim, espera-se que empresas de maior capitalização, tais como as Large Caps, de elevada negociação em bolsa, por período consistente, portanto, de alta liquidez, tendam a apresentar maior nível de conservadorismo e menor informatividade dos lucros e relevância das informações contábeis. Devido às Large Caps apresentarem maior volume de predisclosure de informações específicas, o mercado não tende a reagir fortemente à divulgação das demonstrações contábeis, além de essas firmas sofrerem fortes incentivos para reduzir seu lucro presente, diminuindo atenção e custos políticos.

\subsection{Levantamento dos dados e seleção da amostra}

Os dados foram coletados no sistema Economatica e e também do site da Bolsa de Valores de São Paulo $<w w w . b m f b o v e s p a . c o m . b r>$. Os dados contábeis foram extraídos das demonstrações contábeis consolidadas.

A definição das empresas em Large Caps e Small Caps leva em consideração a capitalização dessas empresas no mercado acionário (BM\&FBovespa) e foram retiradas das composições das carteiras dos índices Mid-Large Cap e Small Cap em 31/3/12, disponíveis no site da Bolsa de Valores de São Paulo <www.bmfbovespa.com.br>. 
A amostra foi composta por empresas não financeiras listadas na Bolsa de Valores de São Paulo (BM\&FBovespa) no período de 2010 a 2012. O período justifica-se em razão da adoção das normas internacionais de contabilidade. As instituições financeiras foram excluídas pelo fato de possuírem um padrão contábil e regulação específicos do Banco Central. Foi coletada, entre ordinárias e preferenciais, apenas uma classe de ação por empresa, aquela que apresentou maior liquidez no período analisado. Foram excluídas também as empresas que não apresentavam informação para alguma das variáveis em estudo.

A amostra contava com 143 empresas que estavam presentes na carteira dos índices Mid-Large Cap (62 empresas) e Small Cap (81 empresas), e totalizavam 429 observações. Ao final da coleta e tratamento dos dados, a amostra para cada modelo está especificada na Tabela 1 a seguir:

Tabela 1

\section{Tratamento dos Dados}

\begin{tabular}{lccc} 
& Conservadorismo & Informatividade & Value Relevance \\
\hline Observações Iniciais (143 firmas/ano) & 429 & 429 & 429 \\
\hline (-) Exclusão dos Setores: Finanças e Seguros & $(39)$ & $(39)$ & $(39)$ \\
\hline (-) Células Vazias ou Observações com Erros & $(44)$ & $(44)$ & $(25)$ \\
\hline (-) Tratamento dos dados - exclusão dos outliers & $(12)$ & $(10)$ & $(17)$ \\
\hline = Amostra Final & 334 & 336 & 348 \\
\hline
\end{tabular}

Fonte: Elaborado pelos autores

Como medida corretiva, os outliers foram retirados, utilizando-se como critério o afastamento entre a média e observação. Dessa forma, observações com mais ou menos de três desvios-padrão foram retiradas da amostra.

\section{Análise dos Resultados}

\subsection{Estatística descritiva e correlação entre as variáveis}

A Tabela 2, a seguir, demonstra a estatística descritiva das variáveis presentes na amostra final do estudo:

Tabela 2

\section{Estatística Descritiva}

\begin{tabular}{cccccc}
\hline Variáveis & Observações & Média & Desvio Padrão & Mínimo & Máximo \\
\hline LLA & 334 & 0,046 & 0,092 & $-0,465$ & 0,290 \\
\hline RE & 334 & 0,426 & 0,679 & $-0,629$ & 3,159 \\
\hline RA & 336 & 0,093 & 0,507 & $-1,407$ & 2,083 \\
\hline P & 348 & 17,470 & 11,133 & 0,240 & 57,032 \\
\hline LPA & 348 & 1,067 & 1,559 & $-5,058$ & 7,275 \\
\hline PLA & 348 & 9,719 & 8,306 & $-0,973$ & 41,820 \\
\hline MB & 348 & 4,466 & 15,893 & 0,321 & 276,630 \\
\hline END & 334 & 0,560 & 0,179 & 0,075 & 1,029
\end{tabular}

Em que: $L L A$ = é o lucro líquido ajustado da empresa no período t; $\mathrm{D}=$ Variável dummy, que será 1 se o retorno econômico for negativo e zero nos demais casos; RE = Retorno econômico por ação da empresa no ano t (ajustado pelo pagamento de dividendos); $R A$ = retorno anormal do valor da empresa no período t; $\mathrm{P}=$ Preço da ação da empresa no tempo t; $\mathrm{PLA}=$ patrimônio líquido por ação da empresa no período t; LPA = Lucro líquido por ação da empresa no período t; $\mathrm{MB}=$ marketto-book da empresa no período t; e END = relação entre o capital de terceiros e o total do ativo no período t. 
A variável "lucro líquido ajustado" apresentou o menor desvio padrão, enquanto a variável market-to-book apresentou o maior desvio padrão. $\mathrm{Na}$ amostra final, as variáveis que apresentaram maior variação foram market-to-book, "preço da ação", "patrimônio líquido por ação" e por último o "lucro por ação".

A Tabela 3, a seguir, apresenta a correlação das variáveis das empresas pertencentes à amostra final, como forma de verificar o grau de associação entre elas.

Tabela 3

Correlação entre as Variáveis

\begin{tabular}{|c|c|c|c|c|c|c|c|}
\hline & LLA & RE & RA & $\mathbf{P}$ & LPA & PLA & МТВ \\
\hline LLA & 1,000 & & & & & & \\
\hline RE & $0,237 * \star *$ & 1,000 & & & & & \\
\hline RA & $0,186 * \star \star$ & $0,827 * \star \star$ & 1,000 & & & & \\
\hline$P$ & $0,164^{* \star *}$ & $-0,062$ & 0,071 & 1,000 & & & \\
\hline LPA & $0,667 * \star *$ & 0,070 & 0,071 & $0,437 * \star *$ & 1,000 & & \\
\hline PLA & $0,184^{\star \star \star}$ & $-0,157 * \star \star$ & $-0,126 * \star$ & $0,563^{* \star *}$ & $0,403^{* \star *}$ & 1,000 & \\
\hline MTB & 0,050 & $0,140 * \star \star$ & $0,165^{* \star *}$ & $0,115^{\star \star}$ & 0,037 & $-0,225 * \star \star$ & 1,000 \\
\hline END & $-0,280 * \star *$ & $-0,089 *$ & $-0,069$ & $-0,003$ & $-0,211 * \star *$ & $-0,150 * \star \star$ & $0,167 * * *$ \\
\hline
\end{tabular}

$\star \star \star, * \star, *$, significante a $1 \%, 5 \%$ e $10 \%$. Em que: $L L A=$ é o lucro líquido ajustado da empresa no período t; RE = Retorno econômico por ação da empresa no ano t (ajustado pelo pagamento de dividendos); $R A=$ retorno anormal do valor da empresa no período t; $\mathrm{P}=$ Preço da ação da empresa no tempo t; PLA = patrimônio líquido por ação da empresa no período t; LPA = Lucro líquido por ação da empresa no período t; MB = market-to-book da empresa no período t; e END = relação entre o capital de terceiros e o total do ativo no período t.

Fonte: Elaborado pelos autores

A correlação apresentou-se significante entre, praticamente, todas as variáveis. As variáveis: "retorno anormal" e "retorno econômico" apresentaram correlação significativa a um nível de 83\%, Outras correlações significativas dizem respeito ao lucro líquido ajustado e ao lucro por ação (67\%), bem como à correlação entre preço da ação e o patrimônio líquido por ação a um nível de 56\%.

\subsection{Resultados dos Modelos}

\subsubsection{Modelo 1: Conservadorismo}

Para analisar o conservadorismo contábil das empresas consideradas Large Caps e Small Caps, a variável "lucro líquido ajustado" foi regredida contra as demais variáveis explanatórias do modelo modificado de Basu (1997).

O Modelo 1.1 foi utilizado para mensurar o conservadorismo entre empresas classificadas como Large Caps e Small Caps. De modo geral, as empresas presentes na amostra do estudo reconhecem oportunamente as perdas econômicas. Logo, a interação entre $\mathrm{D} \times \mathrm{RE}$ foi positiva e estatisticamente significante. A variável de interesse $\mathrm{D} \times \mathrm{RE} \times \mathrm{LC}$ não apresentou valor significante. 
Tabela 4

Regressão Robusta para Conservadorismo

\begin{tabular}{|c|c|c|c|c|c|c|}
\hline \multirow{3}{*}{$\begin{array}{c}\text { Variáveis } \\
\text { Explanatórias }\end{array}$} & \multicolumn{6}{|c|}{ Variável Dependente (LLA - Lucro Líquido Ajustado) } \\
\hline & \multicolumn{2}{|c|}{$\begin{array}{l}\text { Modelo } 1.1 \text { Amostra Completa } \\
\text { (Large Caps e Small Caps) }\end{array}$} & \multicolumn{2}{|c|}{$\begin{array}{l}\text { Modelo } 1.2 \text { Amostra contendo } \\
\text { apenas as empresas Large Caps }\end{array}$} & \multicolumn{2}{|c|}{$\begin{array}{l}\text { Modelo } 1.3 \text { Amostra contendo } \\
\text { apenas as empresas Small Caps }\end{array}$} \\
\hline & Coeficiente & Erro-Padrão & Coeficiente & Erro-Padrão & Coeficiente & Erro-Padrão \\
\hline D & $-0,023$ & 0,022 & 0,001 & 0,026 & $-0,021$ & 0,021 \\
\hline RE & 0,011 & 0,008 & $-0,006$ & 0,018 & 0,012 & 0,008 \\
\hline$D \times R E$ & $0,212 * \star \star$ & 0,072 & $0,283^{* * *}$ & 0,108 & $0,207 * * *$ & 0,068 \\
\hline LC & $0,029 * *$ & 0,015 & & & & \\
\hline$D \times L C$ & 0,016 & 0,034 & & & & \\
\hline $\mathrm{RE} \times \mathrm{LC}$ & $-0,019$ & 0,021 & & & & \\
\hline$D \times R E \times L C$ & 0,047 & 0,132 & & & & \\
\hline END & $-0,143 * \star \star *$ & 0,028 & $-0,039$ & 0,033 & $-0,200 * * *$ & 0,037 \\
\hline Constante & $0,130 * * *$ & 0,014 & $0,097 * * *$ & 0,023 & $0,160 * \star *$ & 0,018 \\
\hline $\mathrm{R}^{2}$ Ajustado & 0,3065 & & 0,1444 & & 0,3850 & \\
\hline Estatística F & 9,10 & & 3,19 & & 16,20 & \\
\hline Sig. & 0,000 & & 0,0151 & & 0,0000 & \\
\hline n..$^{\circ}$ Obs. & 334 & & 150 & & 184 & \\
\hline Média VIF & 3,52 & & 2,26 & & 2,10 & \\
\hline
\end{tabular}

$\star \star \star, \star \star, *$, significante a 1\%,5\% e 10\%. D = Variável dummy, que será 1 se o retorno econômico for negativo e zero nos demais casos; RE = Retorno econômico por ação da empresa i no ano t (ajustado pelo pagamento de dividendos); LC = Variável dummy, assumirá 1 para empresas LargeCaps e 0 para as SmallCaps; e END = Endividamento.

Fonte: Elaborado pelos autores

A variável $D \times R E$, referente às empresas classificadas como Large Caps, apresentou coeficiente positivo e estatisticamente significante $(0,28)$, sugerindo a existência do reconhecimento assimétrico entre as boas e más notícias (perdas econômicas futuras) dos lucros divulgados, no retorno das ações. Para as empresas consideradas Small Caps, também foi possível confirmar a existência do conservadorismo, tendo em vista que o coeficiente $\mathrm{D} \times \mathrm{RE}$ foi estatisticamente significante $(0,207)$. Os valores encontrados corroboram os resultados apurados em pesquisas anteriores Costa et al. (2006), Sarlo Neto et al. (2010) e Moreira, Colauto e Amaral (2010). A variável "endividamento" foi utilizada como controle em todos os modelos. Os resultados não permitem rejeitar a hipótese $\left(\mathrm{H}_{1}\right)$ de que empresas Large Caps são mais conservadoras do que as firmas consideradas Small Caps.

\subsubsection{Modelo 2: Informatividade dos lucros}

Para verificar se o porte das empresas listadas na BMF\&Bovespa, classificadas em Large Caps e Small Caps, é sistematicamente relacionado com a informatividade dos lucros contábeis divulgados, foram realizadas regressões múltiplas. Os resultados encontram-se na Tabela 5.

O primeiro modelo 2.1 foi utilizado para mensurar a relação entre empresas classificadas como Large Caps e Small Caps e a informatividade dos lucros divulgados, e indicou que o conjunto de variáveis utilizadas explica 13,38\% da variância do retorno. A variável de interesse LLA $\times$ LC (interação entre LLA e LC) apresentou valores significantes (10\%) e negativamente correlacionados de 1,13 , o que indica que a divulgação do lucro líquido das empresas Large Caps apresenta impacto na média aritmética do retorno das empresas 1,13 vezes menor do que as empresas Small Caps. 
Tabela 5

Regressão Robusta para Informatividade

\begin{tabular}{|c|c|c|c|c|c|c|}
\hline \multirow{3}{*}{$\begin{array}{l}\text { Variáveis } \\
\text { Explanatórias }\end{array}$} & \multicolumn{6}{|c|}{ Variável Dependente (RA - Retorno Anormal) } \\
\hline & \multicolumn{2}{|c|}{$\begin{array}{l}\text { Modelo } 1.1 \text { Amostra Completa } \\
\text { (Large Caps e Small Caps) }\end{array}$} & \multicolumn{2}{|c|}{$\begin{array}{l}\text { Modelo } 1.2 \text { Amostra contendo } \\
\text { apenas as empresas Large Caps }\end{array}$} & \multicolumn{2}{|c|}{$\begin{array}{l}\text { Modelo } 1.3 \text { Amostra contendo } \\
\text { apenas as empresas Small Caps }\end{array}$} \\
\hline & Coeficiente & Erro-Padrão & Coeficiente & Erro-Padrão & Coeficiente & Erro-Padrão \\
\hline LLA & $1,982^{*}$ & 1,075 & \multirow[t]{3}{*}{0,471} & \multirow[t]{3}{*}{1,625} & \multirow[t]{3}{*}{1,967} & \multirow[t]{3}{*}{1,210} \\
\hline LC & $0,183^{* * *}$ & 0,061 & & & & \\
\hline$L L A \times L C$ & $-1,130 *$ & 0,656 & & & & \\
\hline LLA $\times$ END & $-1,455$ & 1,428 & $-0,359$ & 2,908 & $-1,537$ & 1,632 \\
\hline $\mathrm{LLA} \times \mathrm{MB}$ & $0,269 * * *$ & 0,035 & 0,084 & 0,153 & $0,309 * * \star$ & 0,042 \\
\hline Constante & $-0,068$ & 0,047 & 0,143 & 0,043 & $-0,073$ & 0,049 \\
\hline $\mathrm{R}^{2}$ Ajustado & 0,1338 & & 0,0089 & & 0,1618 & \\
\hline Estatística F & 17,11 & & 0,33 & & 26.35 & \\
\hline Sig. & 0,0000 & & 0,8001 & & 0,0000 & \\
\hline n. ${ }^{\circ}$ Obs. & 336 & & 150 & & 186 & \\
\hline Média VIF & 6,25 & & 9,76 & & 8.39 & \\
\hline
\end{tabular}

$* \star *, * *, *$, significante a $1 \%, 5 \%$ e $10 \% . R A_{i, t}$ é o retorno anormal do valor da empresa i no período t; $L L A_{i, t}$ é o lucro líquido ajustado da empresa i no período t; $L C=$ Variável dummy, assumirá 1 para empresas Large Caps e 0 para as SmallCaps; $e$ END = Endividamento; e MB = market-to-book.

Fonte: Elaborado pelos autores

Nos modelos 2.2 e 2.3, o objetivo é mensurar a informatividade dos lucros divulgados em cada grupo de empresas, Large Caps e Small Caps. A variável objeto de estudo para os dois grupos se mostraram estatisticamente não significantes. Dessa forma, não se pode rejeitar a hipótese $\left(\mathrm{H}_{2}\right)$ de que empresas Large Caps apresentam menor informatividade dos lucros divulgados do que Small Caps.

\subsubsection{Modelo 3: Relevância da informação contábil}

Com o objetivo de testar as hipóteses alternativas de impacto comparativo do porte das empresas, classificados em Large Caps e Small Caps, na relevância da informação contábil, foram realizadas regressões múltiplas, cujos resultados encontram-se na Tabela 6.

Para as três regressões, observa-se que o PLA apresenta coeficiente significativo e positivo, conforme esperado, mas, não, o LPA Esse resultado é consistente com as constatações de Lopes (2002) ao concluir que no Brasil o patrimônio líquido (PLA) é mais relevante em comparação ao lucro (LPA). O resultado é corroborado por Kwon (2009) que também encontrou essa mesma característica em mercados emergentes ou voltados para credores. A variável LC positiva indica que o preço da ação tende a ser maior em Large Caps. A regressão 3.1 analisa o efeito simultâneo do porte pelas variáveis PLA $\times$ LC e LPA $\times$ LC no modelo. Verifica-se que a variável de interesse LPA $\times$ LC é positiva e significativa a $5 \%$, indicando evidência de maior relevância da informação contábil para empresas classificadas entre as Large Caps. 
Tabela 6

Regressão Robusta para Value Relevance

\begin{tabular}{|c|c|c|c|c|c|c|}
\hline \multirow{3}{*}{$\begin{array}{l}\text { Variáveis } \\
\text { Explanatórias }\end{array}$} & \multicolumn{6}{|c|}{ Variável Dependente (P - Preço da Ação) } \\
\hline & \multicolumn{2}{|c|}{$\begin{array}{l}\text { Modelo } 1.1 \text { Amostra Completa } \\
\text { (Large Caps e Small Caps) }\end{array}$} & \multicolumn{2}{|c|}{$\begin{array}{l}\text { Modelo } 1.2 \text { Amostra contendo } \\
\text { apenas as empresas Large Caps }\end{array}$} & \multicolumn{2}{|c|}{$\begin{array}{l}\text { Modelo } 1.3 \text { Amostra contendo } \\
\text { apenas as empresas Small Caps }\end{array}$} \\
\hline & Coeficiente & Erro-Padrão & Coeficiente & Erro-Padrão & Coeficiente & Erro-Padrão \\
\hline PLA & $0,645 * * *$ & 0,138 & $0,708 * * *$ & 0,087 & $0,642^{* * *}$ & 0,138 \\
\hline LPA & 1,039 & 0,749 & $2,187 * * *$ & 0,502 & 1,033 & 0,747 \\
\hline LC & $3,092 * \star$ & 1,447 & & & & \\
\hline$P L A \times L C$ & $-0,167$ & 0,160 & & & & \\
\hline$L P A \times L C$ & $1,742^{*}$ & 0,918 & & & & \\
\hline MB & $0,105^{* *}$ & 0,047 & $0,793 * * *$ & 0,180 & $0,080 * * *$ & 0,027 \\
\hline Constante & $8,109 * * *$ & 0,943 & $6,374^{* * *}$ & 1,293 & $8,249 * * *$ & 0,931 \\
\hline $\mathrm{R}^{2}$ Ajustado & 0,4347 & & 0,5290 & & 0,3172 & \\
\hline Estatística F & 40,95 & & 56,75 & & 24,88 & \\
\hline Sig. & 0,0000 & & 0,0000 & & 0,0000 & \\
\hline n. ${ }^{\circ}$ Obs. & 348 & & 142 & & 206 & \\
\hline Média VIF & 3.43 & & 1.45 & & 1,40 & \\
\hline
\end{tabular}

$\star * *, * *, *$, significante a 1\%,5\% e 10\%. P = Preço da ação da empresa i no tempo t; PLA = patrimônio líquido por ação da empresa i no período t; LPA = Lucro líquido por ação da empresa i no período t; $L C=$ Variável dummy, assumirá 1 para empresas Large Caps e 0 para as Small Caps; e MB=market-to-book.

Fonte: Elaborado pelos autores

Nos modelos 3.2 e 3.3, tanto pelo método da associação relativa (Holthausen \& Watts, 2001), em que se compara os valores de $\mathrm{R}^{2}$ (Small Caps: 0,3172 e Large Caps: 0,5290), quanto pela análise dos coeficientes de regressão de PLA e LPA, observa-se maior relevância dos números contábeis associados às empresas de maior porte, rejeitando, assim, a hipótese $\mathrm{H}_{3}$. Esses resultados são inconsistentes com os achados de Atiase (1985) e Freeman (1987), em que o efeito das informações contidas na publicação dos lucros contábeis seria mais pronunciado em empresas com escassez de informação privada (predisclosure).

\section{Considerações Finais}

O objetivo deste estudo foi verificar se aspectos das informações contábeis, como informatividade, relevância e conservadorismo, podem ser influenciados pelo porte da empresa, medido pelo nível de capitalização, e classificados como Large Caps e Small Caps no mercado acionário brasileiro. Espera-se que empresas de maior capitalização e de elevada negociação em bolsa, por período consistente, portanto de alta liquidez, sofram incentivos para apresentar informações contábeis mais conservadoras, porém de menor informatividade e relevância do que empresas Small Caps.

Com base nas evidências empíricas obtidas, os resultados relativos às hipóteses de trabalhos estão demonstrados no Quadro 1 a seguir: 


\begin{tabular}{lll}
\hline & \multicolumn{1}{c}{ Hipótese } & Resultado \\
\hline $\mathbf{H}_{\mathbf{1}}$ & $\begin{array}{l}\text { Empresas classificadas como Large Caps possuem maior nível de conservadorismo do que } \\
\text { Small Caps. }\end{array}$ \\
\hline $\mathbf{H}_{\mathbf{2}}$ & $\begin{array}{l}\text { Empresas classificadas como Large Caps apresentam menor informatividade nos lucros } \\
\text { divulgados do que Small Caps. }\end{array}$ \\
\hline $\mathbf{H}_{\mathbf{3}}$ & Empresas classificadas como Large Caps possuem menor value relevance do que Small Caps. & Rejeitada \\
\hline
\end{tabular}

Quadro 1. Resumo dos Resultados

Fonte: Elaborado pelos autores

Sobre os resultados encontrados, pode-se levantar um conjunto de evidências sobre o impacto do porte das firmas na informação contábil.

Verificou-se que empresas Large Caps apresentaram relação positiva e significativa com o conservadorismo, sugerindo a existência do reconhecimento assimétrico entre as boas e más notícias (perdas econômicas futuras) dos lucros divulgados, no retorno das ações. Esse resultado corrobora a teoria que afirma que grandes empresas sofrem incentivos para reduzir o lucro presente, de forma a diminuir a atenção política (Iudícibus \& Lopes, 2008).

Por meio dos resultados encontrados para o Modelo 2, sugere-se que empresas Large Caps apresentam menor informatividade dos lucros do que Small Caps, devido à maior reação do mercado frente à divulgação dos lucros contábeis nas firmas Small Caps do que nas de Large Caps. Os resultados apoiam estudos anteriores, como de Atiase (1985) e Freeman (1987), que concluíram que devido à maior demanda de predisclosure de informações específicas por grandes empresas, quando da divulgação do lucro contábil, a reação do mercado a essa informação seria menor do que em pequenas empresas.

Nos resultados apurados no Modelo 3, de relevância da informação contábil, foi verificado que os números contábeis mostraram-se associados de maneira mais relevante ao preço das ações em empresas Large Caps em comparação com as Small Caps, contrariando os resultados de Atiase (1985) e Freeman (1987), em que o efeito das informações contidas na publicação dos lucros contábeis seria mais pronunciada em empresas com escassez de informação privada (predisclosure).

O conjunto dos resultados encontrados sugerem que o porte das empresas influencia as métricas pesquisadas, informatividade dos lucros, relevância da informação contábil e conservadorismo. Contudo, estes resultados devem ser vistos com cautela, ponderados por elementos que não foram incorporados nesta pesquisa. Os resultados encontrados indicam que a informação contábil é mais relevante e apresenta maior informatividade para as empresas Small Caps. Porém, essas evidências podem estar associadas a fatores que não foram considerados nos modelos estimados, tais como a presença de intermediários informacionais (ex.: analistas de mercado), que, preferencialmente, acompanham as Large Caps, fornecendo recomendações sobre as demonstrações financeiras divulgadas.

O tamanho da base de dados que deu origem às amostras, devido à composição de os índices da BM\&Fbovespa (Mid-Large Caps e Small Caps) restringirem-se a uma lista com poucas empresas, bem como o reduzido período de pesquisa, de 2010 a 2012, podem ser definidos como limitadores para a estudo em questão.

Para futuras pesquisas indica-se a investigação de outros modelos para mensurar diversos aspectos da informação contábil, como timeliness e gerenciamento de resultados, e também o uso de outras formas de classificação do porte da empresa, tal como a presença em Bolsa. Adicionalmente, novos estudos poderiam adotar outras metodologias. Uma alternativa interessante seria a realização de um estudo de evento. 


\section{Referências}

Almeida, J. E. F. de. (2010). Qualidade da informação contábil em ambientes competitivos. Tese de Doutorado, Universidade de São Paulo, São Paulo, SP, Brasil. Recuperado em http://www.teses.usp.br/ teses/disponiveis/12/12136/tde-29112010-182706/

Almeida, J. E. F. de, Sarlo Neto, A., Bastianello, R. F., \& Moneque, E. Z. (2012). Alguns aspectos das práticas de suavização de resultados no conservadorismo das companhias abertas listadas na BM \& FBovespa. Revista Contabilidade \& Finanças, 23(58), pp. 65-75. Recuperado em http://www.revistas.usp.br/rcf/article/view/34348

Atiase, R. K. (1985). Predisclosure Information, Firm Capitalization, and Security Price Behavior Around Earnings Announcements. Journal of Accounting Research, 23(1), pp. 21-36. doi.org/10.2307/2490905

Ball, R., \& Brown, P. (1968). An Empirical Evaluation of Accounting Income Numbers. Journal of Accounting Research, 6(2), pp.159-178. doi.org/10.2307/2490232

Banz, R. W. (1981). The relationship between return and market value of common stocks. Journal of Financial Economics, 9(1), pp.3-18. doi.org/10.1016/0304-405X(81)90018-0

Barth, M. E., Beaver, W. H., \& Landsman, W. R. (2001). The relevance of the value relevance literature for financial accounting standard setting: another view. Journal of Accounting and Economics, 31(1-3), pp.77-104. doi.org/10.1016/S0165-4101(01)00019-2

Basu, S. (1997). The conservatism principle and the asymmetric timeliness of earnings. Journal of Accounting and Economics, 24(1), pp.3-37. doi.org/10.1016/S0165-4101(97)00014-1

Beaver, W. H. (1968). The Information Content of Annual Earnings Announcements. Journal of Accounting Research, 6, pp.67-92. doi.org/10.2307/2490070

Brugni, T. V., Neto, A. S., Bastianello, R. F., \& Paris, P. K. S. (2012). Influências de dividendos sobre a Informatividade dos Lucros: Evidências empíricas na BM\&FBOVESPA. Revista Universo Contábil, 8(3), pp.82-99. Recuperado em http://proxy.furb.br/ojs/index.php/universocontabil/article/view/2556 doi:10.4270/ruc.2012323

Chan, L. K. C., Hamao, Y., \& Lakonishok, J. (1991). Fundamentals and Stock Returns in Japan. The Journal of Finance, 46(5), pp.1739-1764. doi.org/10.2307/2328571

Collins, D. W., Kothari, S. P., \& Rayburn, J. D. (1987). Firm size and the information content of prices with respect to earnings. Journal of Accounting and Economics, 9(2), pp.111-138. doi.org/10.1016/01654101(87)90002-4

Costa, F. M. da, Lopes, A. B., \& Costa, A. C. de O. (2006). Conservadorismo em cinco países da América do Sul. Revista Contabilidade \& Finanças, 17(41), pp.7-20. doi.org/10.1590/S1519-70772006000200002

Dechow, P. M., Ge, W., \& Schrand, C. (2010). Understanding earnings quality: A review of the proxies, their determinants and their consequences. Journal of Accounting and Economics, 50(2-3), pp.344401. doi.org/10.1016/j.jacceco.2010.09.001

Dijk, M. A. van. (2011). Is size dead? A review of the size effect in equity returns. Journal of Banking \& Finance, 35(12), pp. 3263-3274. doi.org/10.1016/j.jbankfin.2011.05.009

Easton, P. D., \& Harris, T. S. (1991). Earnings As an Explanatory Variable for Returns. Journal of Accounting Research, 29(1), pp.19-36. doi.org/10.2307/2491026

Eun, C. S., Huang, W., \& Lai, S. (2008). International Diversification with Large- and Small-Cap Stocks. Journal of Financial and Quantitative Analysis, 43(02), pp. 489-524. /doi.org/10.1017/ S0022109000003604 
Fan-fah, C., Mohd, S., \& Nasir, A. (2008). Earnings Announcements: The Impact of Firm Size on Share Prices. Journal of Money, Investment and Banking, 3, pp.36-46.

Francis, J., \& Schipper, K. (1999). Have Financial Statements Lost Their Relevance? Journal of Accounting Research, 37(2), pp. 319-352. doi.org/10.2307/2491412

Francis, J., Schipper, K., \& Vincent, L. (2005). Earnings and dividend informativeness when cash flow rights are separated from voting rights. Journal of Accounting and Economics, 39(2), pp. 329-360. doi.org/10.1016/j.jacceco.2005.01.001

Freeman, R. N. (1987). The association between accounting earnings and security returns for large and small firms. Journal of Accounting and Economics, 9(2), pp. 195-228. doi.org/10.1016/0165-4101(87)90005-X

Glaser, M., \& Schaarschmidt, S. (2012). Market Integration and Small Stock Returns: A Co-Movement Analysis (Working Paper No. ID 2021195). Rochester, NY: Social Science Research Network. Recuperado em http://papers.ssrn.com/abstract=2021195 doi.org/10.2139/ssrn.2021195

Grant, E. B. (1980). Market Implications of Differential Amounts of Interim Information. Journal of Accounting Research, 18(1), pp. 255-268. doi.org/10.2307/2490401

Holthausen, R. W., \& Watts, R. L. (2001). The relevance of the value-relevance literature for financial accounting standard setting. Journal of Accounting and Economics, 31(1-3), pp. 3-75. doi.org/10.1016/ S0165-4101(01)00029-5

Hungarato, A., \& Lopes, A. B. (2008). Value-Relevance dos Gastos em P\&D para o Preço das Ações das Empresas Brasileiras Negociadas na Bovespa. Simpósio de Gestão da Inovação Tecnológica. Brasília, DF, Brasil, 25. Recuperado em http://www.fucape.br/_public/producao_cientifica/2/Arildo\%20 Hungarato.pdf

Iudícibus, S. de, \& Lopes, A. B. (2008). Teoria avançada da contabilidade. São Paulo: Atlas.

Jones, J. J. (1991). Earnings Management During Import Relief Investigations. Journal of Accounting Research, 29(2), pp. 193-228. doi.org/10.2307/2491047

Kothari, S. P., \& Zimmerman, J. L. (1995). Price and return models. Journal of Accounting and Economics, 20(2), pp. 155-192. doi.org/10.1016/0165-4101(95)00399-4

Kouser, R., Awan, A., Gul-e-Rana, \& Shahzad, F. A. (2011). Firm Size, Leverage And Profitability: Overriding Impact Of Accounting Information System. Business and Man Agement Review, 1(10), pp. 58-64. Recuperado em http://www.businessjournalz.org/articlepdf/BMR_11016.pdf

Kwon, G. J. (2009). The Value Relevance of Book Values, Earnings and Cash flows: Evidence from South Korea. International Journal of Business and Management, 4(10), p. 28. doi.org/10.5539/ijbm. v4n10P28

Lima, J. B. N. de. (2011). A relevância da informação contábil e o processo de convergência para as normas IFRS no Brasil. Tese de Doutorado, Universidade de São Paulo, São Paulo, SP, Brasil. Recuperado em http://www.teses.usp.br/teses/disponiveis/12/12136/tde-24032011-185955/

Liu, J., \& Liu, C. (2007). Value Relevance of Accounting Information in Different Stock Market Segments: The Case of Chinese A-, B-, and H-Shares. Journal of International Accounting Research, 6(2), pp. 55-81. doi.org/10.2308/jiar.2007.6.2.55

Lopes, A. B. (2002). The Value Relevance of Brazilian Accounting Numbers: An Empirical Investigation (Working Paper No. ID 311459). Rochester, NY: Social Science Research Network. Recuperado em http://papers.ssrn.com/abstract=311459 doi.org/10.2139/ssrn.311459

Lopes, A. B., \& Martins, E. (2005). Teoria da Contabilidade: Uma Nova Abordagem. São Paulo: Atlas. 
Macedo, M. A. da S., Machado, M. A. V., Murcia, F. D. R., \& Machado, M. R. (2011). Análise do impacto da substituição da DOAR pela DFC: um estudo sob a perspectiva do value-relevance. Revista Contabilidade \& Finanças, 22(57), pp. 299-318. doi.org/10.1590/S1519-70772011000300005

Moreira, R. de L., Colauto, R. D., \& Amaral, H. F. (2010). Conservadorismo Condicional: estudo a partir de variáveis econômicas. Revista Contabilidade \& Finanças, 21(54), pp. 64-84. doi.org/10.1590/ S1519-70772010000300006

Ohlson, J. A. (1995). Earnings, Book Values, and Dividends in Equity Valuation. Contemporary Accounting Research, 11(2), pp. 661-687. doi.org/10.1111/j.1911-3846.1995.tb00461.x

Papadatos, K., \& Bellas, A. (2011). The Value Relevance of Accounting Information Under Greek and International Financial Reporting Standards: The Influence of Firm-Specific Characteristics. International Research Journal of Finance and Economics, 76, p. 6. Recuperado em http://papers.ssrn. com/abstract $=1963369$

Paulo, E., Antunes, M. T. P., \& Formigoni, H. (2008). Conservadorismo contábil nas companhias abertas e fechadas brasileiras. Revista de Administração de Empresas, 48(3), pp. 46-60. doi.org/10.1590/ S0034-75902008000300005

Santos, O. M. D., Lopes, A. B., \& Silva, P. D. A. D. (2010). Value Relevance dos Métodos Contábeis Full Cost e Successful Efforts em Empresas Petrolíferas e Considerações Sobre A Futura Norma Internacional das Atividades Extrativistas. Congresso USP de Controladoria e Contabilidade. São Paulo, SP, Brasil, 10. Recuperado em http://www.congressousp.fipecafi.org/web/artigos102010/188.pdf

Sarlo Neto, A. (2009). Relação entre a estrutura de propriedade e a informatividade dos lucros contábeis no mercado brasileiro. Tese de Doutorado. Universidade de São Paulo, São Paulo, SP, Brasil. Recuperado em http://www.teses.usp.br/teses/disponiveis/12/12136/tde-22042009-143539/

Sarlo Neto, A., Rodrigues, A., \& Almeida, J. E. F. de. (2010). Concentração de votos e acordo de acionistas: influências sobre o conservadorismo. Revista Contabilidade \& Finanças, 21(54), pp. 6-22. doi. org/10.1590/S1519-70772010000300002

Sutton, T. G. (1988). The proposed introduction of current cost accounting in the U.K.: Determinants of corporate preference. Journal of Accounting and Economics, 10(2), pp. 127-149. doi. org/10.1016/0165-4101(88)90017-1

Wang, D. (2006). Founding Family Ownership and Earnings Quality. Journal of Accounting Research, 44(3), pp. 619-656. doi.org/10.1111/j.1475-679X.2006.00213.x

Watts, R. L., \& Zimmerman, J. L. (1979). The Demand for and Supply of Accounting Theories: The Market for Excuses. The Accounting Review, 54(2), pp. 273-305. Recuperado em http://www.jstor.org/ stable/245516

Watts, R. L. (2003). Conservatism in Accounting - Part I: Explanations and Implications (Working Paper No. ID 414522). Rochester, NY: Social Science Research Network. Recuperado em http://papers. ssrn.com/abstract $=414522$

Wong, J. (1988). Economic incentives for the voluntary disclosure of current cost financial statements. Journal of Accounting and Economics, 10(2), pp. 151-167. doi.org/10.1016/0165-4101(88)90018-3 